\title{
Body size-related constraints on the movement behaviour of the arctic notostracan Lepidurus arcticus (Pallas, 1973) under laboratory conditions
}

\author{
Giorgio Mancinelli ${ }^{1} \cdot$ Vittorio Pasquali $^{2}$
}

Received: 9 November 2015/ Accepted: 8 February 2016

(C) Accademia Nazionale dei Lincei 2016

\begin{abstract}
The movement behaviour of individuals has long been acknowledged as a key determinant of species distribution in space and time. Information on benthic macroinvertebrates from aquatic habitats are still scant, however, and for polar species are virtually nonexistent. Here, the influence of body size on the movement behaviour of the arctic notostracan Lepidurus arcticus (Pallas) was examined under resource-free laboratory conditions. The mean step length, total path length and average speed were determined for specimens varying in body dry mass by six orders of magnitude. The scale-independent fractal dimension D was used to quantify movement path tortuosity. Among the different movement metrics considered, the body size of specimens scaled significantly only with path tortuosity; specifically, a negative relationship with a breakpoint was observed between individual body masses and the $\mathrm{D}$ values of the respective movement paths. The results are discussed considering similar results obtained
\end{abstract}

This peer-reviewed article is a result of the multi and interdisciplinary research activities based at the Arctic Station "Dirigibile Italia", coordinated by the "Dipartimento Scienze del Sistema Terra e Tecnologie per l'Ambiente" of the National Council of Research of Italy.

Electronic supplementary material The online version of this article (doi:10.1007/s12210-016-0512-z) contains supplementary material, which is available to authorized users.

Giorgio Mancinelli

giorgio.mancinelli@unisalento.it

1 Department of Biological and Environmental Sciences and Technologies, Ecotekne Centre, University of Salento, Prov.le Lecce-Monteroni, 73100 Lecce, Italy

2 Neuroscience Section, Department of Psychology, Sapienza University of Rome, Via dei Marsi, 78, 00185 Rome, Italy for benthic crustaceans from temperate habitats. Additionally, their implications for future investigations explicitly considering temperature effects on movement behaviour are briefly considered.

Keywords Arctic tadpole shrimp - Locomotor activity Individual differences $\cdot$ Fractal dimension

\section{Introduction}

Quantifying and understanding movement is critical for a wide range of questions in basic and applied ecology (Holyoak et al. 2008; Pasquali and Sbordoni 2014; Demšar et al. 2015). Crucial aspects of animal behaviour, population genetics, predator-prey dynamics, and conservation biology all depend upon the strategies adopted by organisms to explore the surrounding space in search of food, to shelter from predators, and for mating (Nathan et al. 2008; Liedvogel et al. 2013).

Local and landscape-scale movements, habitat use, and dispersal of vertebrates have been investigated for more than 50 years (Kissling et al. 2014 and literature cited). Quantitative studies on invertebrates are relatively less common, and the majority of them have focused on terrestrial insects and crustaceans (e.g. With 1994a, b; Angilletta et al. 2008; Allema et al. 2012, 2014; Kissling et al. 2014; Barnes et al. 2015). Only recently, attention has been given to brackish Mediterranean isopods (Mancinelli 2010; Potenza and Mancinelli 2010) and, subsequently, to other representative gastropod and crustacean species occurring in temperate environments (Chapperon and Seuront 2011, 2013; Longo et al. 2015; Augusiak and Van den Brink 2015).

Noticeably, to date no efforts have been made to investigate the movement behaviour of polar invertebrates 
[but see Pasquali (2015) for a recent counterexample]. Polar regions are currently experiencing some of the most rapid and severe climate change on Earth. Indeed, during the twentieth century, Arctic air temperatures increased by approximately $5{ }^{\circ} \mathrm{C}$, a tenfold higher increase rate than that estimated at a global scale; additionally, an increase of up to $7{ }^{\circ} \mathrm{C}$ in the Arctic is predicted over the next century (Nielsen and Wall 2013 and literature cited). Poikilothermic species, aquatic invertebrates among others, are expected to be particularly sensitive to climate change, since the physiological and metabolic processes related to the search of trophic resources in the environment and their subsequent ingestion and assimilation are highly sensitive to temperature (e.g. see Richardson 2008 for zooplankton; Lemoine and Burkepile 2012).

Here, we investigated the movement behaviour of the arctic notostracan Lepidurus arcticus (Pallas 1973). Commonly known as Arctic tadpole shrimp, the species has a wide circumpolar distribution in freshwater water bodies of the northern hemisphere (Rogers 2001). The species life cycle has been described in detail in Borgstrøm and Larsson (1974), Wojtasik and Bryłka-Wołk (2010), and Lakka (2013). In brief, L. arcticus has an annual life cycle, starting when bottom sediments defrost. After the overwintering hibernated eggs hatch, five instars are observed before the adult stage is reached, with maximum sizes observed in fall, when females lay eggs in littoral zones before dying. The mode of reproduction has been described as parthenogenetic with unisexual populations (Hessen et al. 2004) and occasional occurrence of males [1:100 male:female ratio; 1:16 in Solvatnet pond: Lakka (2015)] as well as hermaphroditic (Sassaman 1991). Individuals have a pelagic life style until they reach the 5th instar; consequently, they become benthic and start preying on other benthic crustaceans, including conspecifics (Einarsson 1979; Christoffersen 2001; Lakka 2015). Stomach content analyses suggested that the Arctic tadpole shrimp can also feed on detritus, bacteria and vegetal matter including moss leaves, lichens, diatoms, and green algae (Einarsson 1979). L. arcticus plays also a significant role in polar food webs in the transfer of matter and energy towards higher trophic levels, being an important food item in the diet of birds (e.g. Sterna paradisaea, Calidris maritime) and fish (e.g. Salmo trutta, Salvelinus alpinus; Lakka 2013 and literature cited).

In the present study a core question was addressed: do significant intra-specific, body size-related variations in movement patterns occur in Lepidurus arcticus? Intriguingly, the scant body of information available for brackish isopods and amphipods (Mancinelli 2010; Longo et al. 2015) indicates that strong variations in movement complexity occur at an individual scale, i.e. movement trajectories shift progressively towards simpler, more linear patterns as the individual's size increases (see Mancinelli 2009 for a more complete discussion of related conceptual assumptions). Here we verified the generality of these findings with $L$. arcticus. Analyses were carried out under resource-free laboratory conditions and were performed on individuals characterized by a huge variability in body size. The coordinates of movement paths were acquired using a video-tracking system; they were used to calculate for each specimen the total path length, the average speed, and the path tortuosity, estimated by the fractal dimension D.

\section{Materials and methods}

\subsection{Field collection}

Lepidurus arcticus specimens were sampled in Solvatnet pond $\left(78^{\circ} 56^{\prime} \mathrm{N}, 11^{\circ} 57^{\prime} \mathrm{E}\right)$, a small, shallow water body located in Ny-Ålesund $\left(78^{\circ} 55^{\prime} \mathrm{N}, 11^{\circ} 56^{\prime} \mathrm{E}\right)$, an arctic expedition base on the Brøggerhalvoya peninsula on the west coast of the Spitsbergen archipelago (Fig. 1). Samples were collected on August 10, 2014 during CNR Arctic Summer Campaign 2014, using a hand-held net $(0.5 \mathrm{~mm}$ mesh size). Adult specimens with a carapace length $>4$ mm (Lakka 2013) were selected on site and transferred to the laboratory into containers filled with filtered $(0.125 \mathrm{~mm})$ pond water (FPW hereafter). 100 Arctic tadpole shrimps were subsequently maintained for 7 days in two $25-\mathrm{L}$ aerated aquaria $(48 \times 23 \times 28 \mathrm{~cm})$ filled with FPW at $10^{\circ} \mathrm{C}$ with a natural light photoperiod. They were fed ad libitum with decaying macroalgae and living Daphnia magna individuals collected at the sampling site and renewed every day. The constant occurrence of food in excess allowed to keep at negligible levels mortality and cannibalism: at the start of the movement trials only nine specimens were not found in the aquaria.

\subsection{Experimental setup and acquisition of movement data}

The general experimental setup is described in detail in Longo et al. (2015). In brief, $24 \mathrm{~h}$ before the start of the trials, 50 specimens spanning the whole body size range were randomly selected from the aquaria and isolated into individual resource-free bottles with $100 \mathrm{ml}$ FPW. A circular arena was made with a white plastic dish $300 \mathrm{~mm}$ wide and $1 \mathrm{~cm}$ high. A VGA CCD webcam connected to a laptop was located azimuthally over the arena at a distance of $50 \mathrm{~cm}$, with a field of view $320 \mathrm{~mm}$ width.

At the start of each trial, the arena was filled with FPW, and a single specimen was placed at its centre. A white cylindrical screen $40 \mathrm{~cm}$ high was located around the arena to provide a uniform visual background. After acclimating 


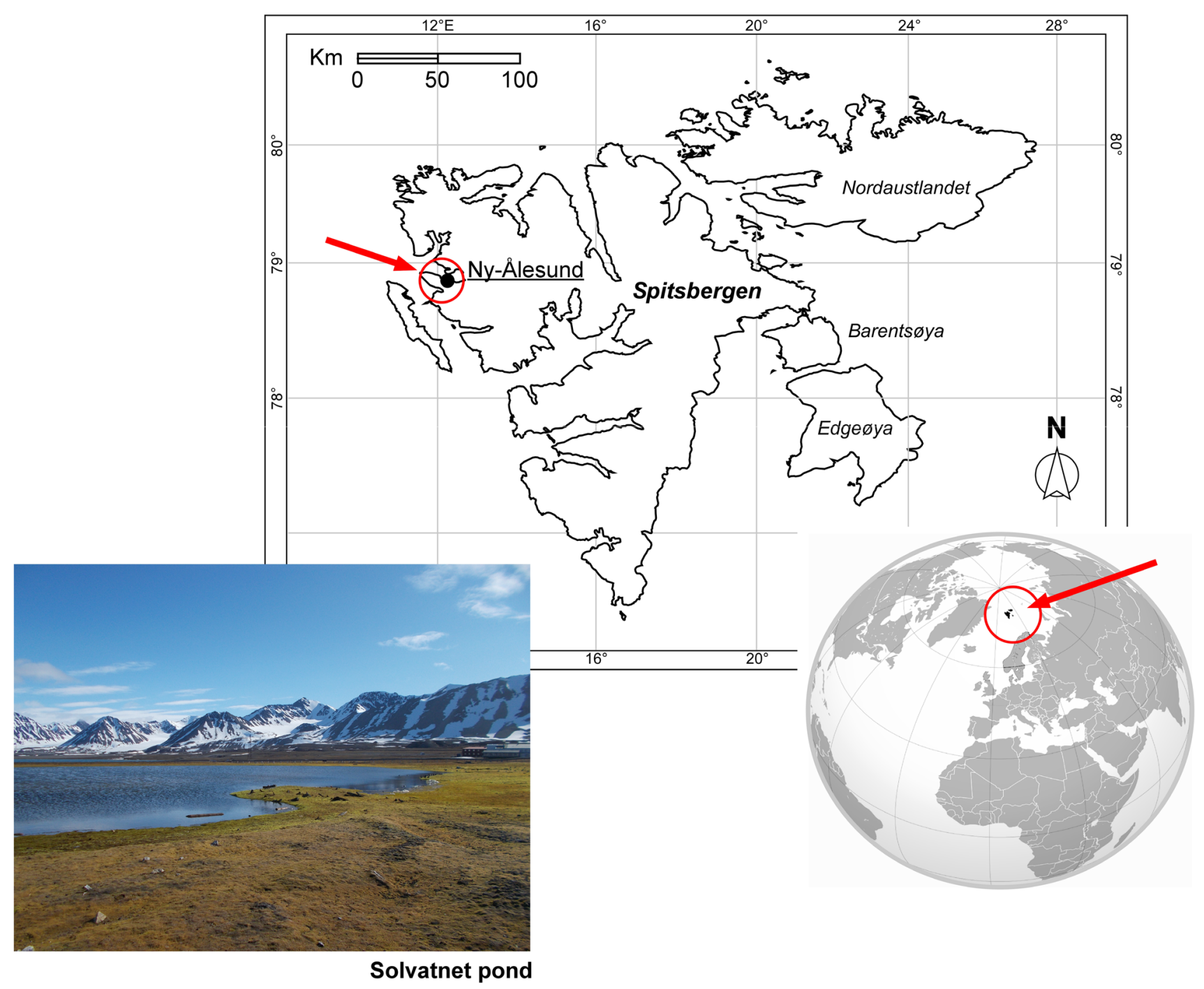

Fig. 1 Ny-Ålesund: location in the Spitsbergen archipelago, and picture of Solvanet pond (photo credit: V. Pasquali)

the specimen for $1 \mathrm{~min}$, the video recording procedure was started. At the end of the trial, the specimen was removed; the arena was emptied and blotted dry to remove chemical cues. The procedure were repeated for all the 50 specimens. All measurements were carried out at a temperature of $10^{\circ} \mathrm{C}$ and at natural light conditions (24 h light; approx. $130 \mathrm{~W} \mathrm{~m}^{-2}$ : Mazzola et al. 2016).

Video files $(640 \times 480$ pixels $)$ were acquired at a temporal resolution of $0.5 \mathrm{~Hz}$ for $5 \mathrm{~min}$ and stored. The behavioural tracking system Ethovision (EthoVision 3.1 software; Noldus, Wageningen, the Netherlands) was used to extract movement data as time-referenced $x$ and $y$ coordinates calibrated in $\mathrm{mm}$. Subsequently, for each specimen coordinate values were classified as belonging to wall-following or exploratory paths (Jeanson et al. 2003). Coordinates were included in the first category when the specimen was at a distance $<0.5 \mathrm{~mm}$ from the wall of the arena. Wall-following paths were considered biased and discarded; further analyses were carried out on exploratory paths only, hereafter referred as free movement paths (FMPs). After each trial, specimens were euthanized by placing them on blotting paper, dried $\left(60{ }^{\circ} \mathrm{C}\right.$ for at least $72 \mathrm{~h}$ ) and individually weighed to the nearest $0.01 \mathrm{mg}$.

\subsection{Data analysis}

For each specimen, FMPs were individually analysed using the freeware Fractal 5.24 (Nams and Bourgeois 2004). The mean step length (mean distance travelled between two consecutive locations) and the total path length (the total distance travelled, or gross displacement) were directly calculated by Fractal in millimetres; average speeds were computed by dividing total path length by the duration of the path, calculated by multiplying the path step number 
for 0.5 (image acquisition rate). Average speeds were expressed in millimetres per second. In addition, movement tortuosity was estimated by the path fractal dimension $\mathrm{D}$, calculated by a resampling procedure of the divider method to correct for biases (Nams 2006). D values were estimated using a window range of 0.25 ; scale independency of D estimations (sensu Turchin 1996) was checked by visually inspecting $\mathrm{D}$ versus scale plots produced by Fractal.

FMPs were used to calculate the mean and standard error (SE) of each metrics for each specimen. For univariate statistical analyses, the assumption of homogeneity of variances was checked using Cochran's $C$ test, and transformations were used if necessary. Normality was tested using the Kolmogorov-Smirnov test. When required, post hoc comparisons of means were performed using Tukey HSD tests. Following Mancinelli et al. (2005) and Longo and Mancinelli (2014), movement metrics were regressed against individual body size (expressed as $\mathrm{mg}$ DM) by least squares using a simple linear (SL hereafter), or, alternatively, a piece-wise linear model with a single breakpoint (SLR). Regressions were performed using the iterative procedure implemented in the segmented $\mathrm{R}$ package (Muggeo 2008). Model comparisons were carried out using a parsimonious procedure (Burnham and Anderson 2002) based on the second-order Akaike Information Criterion AICc (Sugiura 1978; after Akaike 1974).

\section{Results}

Of the original group of 50 Lepidurus arcticus specimens subjected to movement analysis, it was possible to obtain reliable estimations of movement metrics for 48 of them. Two specimens were excluded due to their extremely limited mobility.

Specimens included in the analyses varied in body dry mass by six orders of magnitude (Table 1; see also Tab. I in Electronic Supplementary Materials). From a qualitative point of view, the movement path of the analysed specimens was generally characterized by an initial exploration of the environment, with the individual following free, convoluted trajectories across the arena (Fig. 2); subsequently, in the later stage of the trials notostracans adopted two drastically different movement strategies: they preferentially remained in contact with the wall, moving along it as for in search of an escape, and only sporadically attempting to move across the arena; alternatively, they continued to move across the area exploring the available space until the end of the trial period.

These qualitative observations reflected on a high interindividual heterogeneity in the number of analysed FMPs, ranging between 3 and 22 (Table 1); noticeably, a
Table 1 Individual dry mass, number of free movement paths (FMP), movement metrics (step length, path length, movement speed) and fractal dimension $D$ of movement trajectories of Lepidurus arcticus specimens included in the analysis

\begin{tabular}{lcc}
\hline & \multicolumn{1}{c}{ Mean } & Min-max \\
\hline Individual dry mass $(\mathrm{mg})$ & $4.75 \pm 0.22$ & $1.71-7.39$ \\
FMP $\left(n\right.$ ind $\left.^{-1}\right)$ & $7.04 \pm 0.61$ & $3-22$ \\
Step length $(\mathrm{mm})$ & $8.68 \pm 0.73$ & $0.95-21.23$ \\
Path length $(\mathrm{mm})$ & $874.65 \pm 91.02$ & $137.86-2993.44$ \\
Movement speed $\left(\mathrm{mm} \mathrm{s}^{-1}\right)$ & $16.49 \pm 1.41$ & $2.01-43.35$ \\
Fractal dimension D & $1.08 \pm 0.01$ & $1.01-1.18$ \\
\hline
\end{tabular}

Mean \pm SE. Minimum and maximum values are also reported

negligible relationship was observed between the number of FMPs and individual body mass $(r=0.03, P=0.83,46$ $d f)$.

The mean step length, mean path length and mean movement speed of Arctic tadpole shrimps were highly variable, with approximately a 20 -fold inter-individual variation (Table 1). No significant relationships were observed between the aforementioned metrics and the individual mass of notostracans (Fig. 3; $\max r=0.25$, $P=0.09,46 d f$, determined for step length vs. body mass). Conversely, the fractal dimension $\mathrm{D}$ was negatively related to body size (Fig. 4). Overall, individuals with a body mass lower than $3 \mathrm{mg}$ were characterized by tortuous, convoluted FMPs, reflecting in $D$ values comprised between $1.11 \pm 0.01$ and $1.18 \pm 0.02$ (mean $\pm \mathrm{SE}$ ); path tortuosity dropped abruptly with increasing body mass, and larger individuals were characterized by movement trajectories approximately linear, with $D$ values close to 1 .

The regression analysis confirmed the peculiarities of the pattern characterizing the body size-tortuosity relationship: indeed, compared to a simple linear regression model, the parsimonious procedure based on Akaike Information Criterion selected the SLR (Table 2), characterized by a breakpoint $\mathrm{C}$ at $3.81 \pm 0.34 \mathrm{mg}$ (mean $\pm \mathrm{SE}$ ), as the best fitting model (Fig. 4).

\section{Discussion}

The main results of the present study indicated that movement metrics scaled weakly with the body size of Lepidurus arcticus specimens; the only exception was represented by path tortuosity, quantified by the fractal dimension D. A significant, negative relationship was observed, indicating that the larger the Arctic tadpole shrimp the more linear is its movement path. Conversely, small notostracans showed more tortuous and convoluted trajectories. These findings are consistent with information on other crustaceans from temperate habitats such as 
Fig. 2 Exemplificative movement path of a Lepidurus arcticus specimen acquired during the study. The example is limited to the first $120 \mathrm{~s}$ of video acquisition; time is plotted along the Z-axis allowing for a tridimensional representation of the trajectory. Drawing of $L$. arcticus modified from plate XXII (described as $L$. glacialis) in Baird (1852)

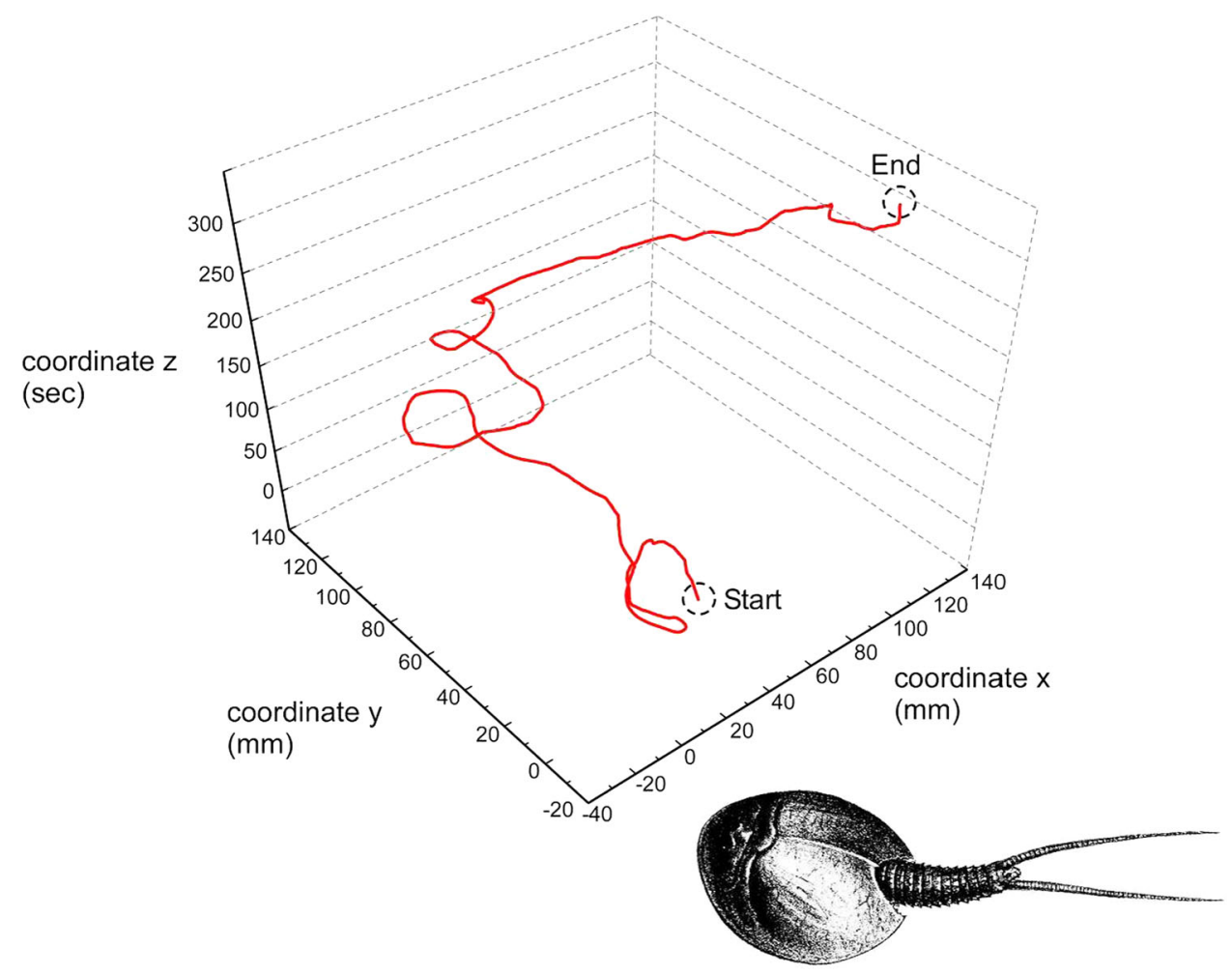

Fig. 3 a Mean step length $(\mathrm{mm})$ and $\mathbf{b}$ total path length $(\mathrm{mm})$ characterizing the movement paths of Lepidurus arcticus specimens in relation to their body sizes (individual dry mass, in $\mathrm{mg}$ ). Scale bars $\pm 1 \mathrm{SE}$. The average speed (expressed in $\mathrm{mm} \mathrm{s}^{-1}$ ) of each individual was highly correlated with the mean step length $(r=0.97$,

$P<0.0001,46 d f$ ) and for the sake of conciseness it is not reported

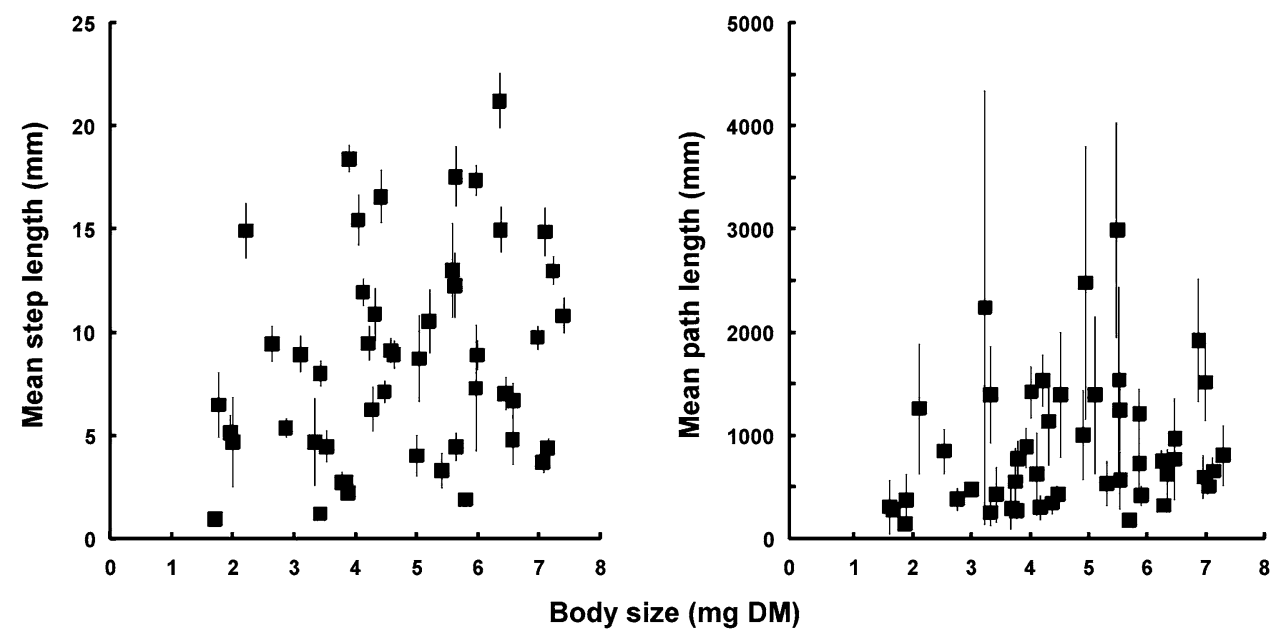

isopods and amphipods (Potenza and Mancinelli 2010; Mancinelli 2010; Longo et al. 2015; Augusiak and Van den Brink 2015). Animal movement can be viewed as the result of a constant "dialogue" between external factors determined by the chemical-physical features of the surrounding environment and animal internal states related to morphology, metabolism, and physiology. This dialogue regulates the motion capacities of an organism to finally produce the actual trajectory (Nathan et al. 2008; Prevedello et al. 2010), and, in turn, its distribution in space and time (Mueller and Fagan 2008). The present results, and their consistency with previous studies, suggest that for benthic crustaceans a general, a-specific connection occurs between the movement strategy and the individual body size, independently from external drivers related to, e.g. climate or characteristics of the benthic habitat.

At an inter-specific level, negative relationships between path tortuosity and body size have been observed in the field for a phylogenetically diverse set of species in both aquatic and terrestrial environments, from invertebrates to mammals (With 1994a; Etzenhouser et al. 1998; With et al. 1999; McDonald and St Clair 2004; Prevedello et al. 2010). 


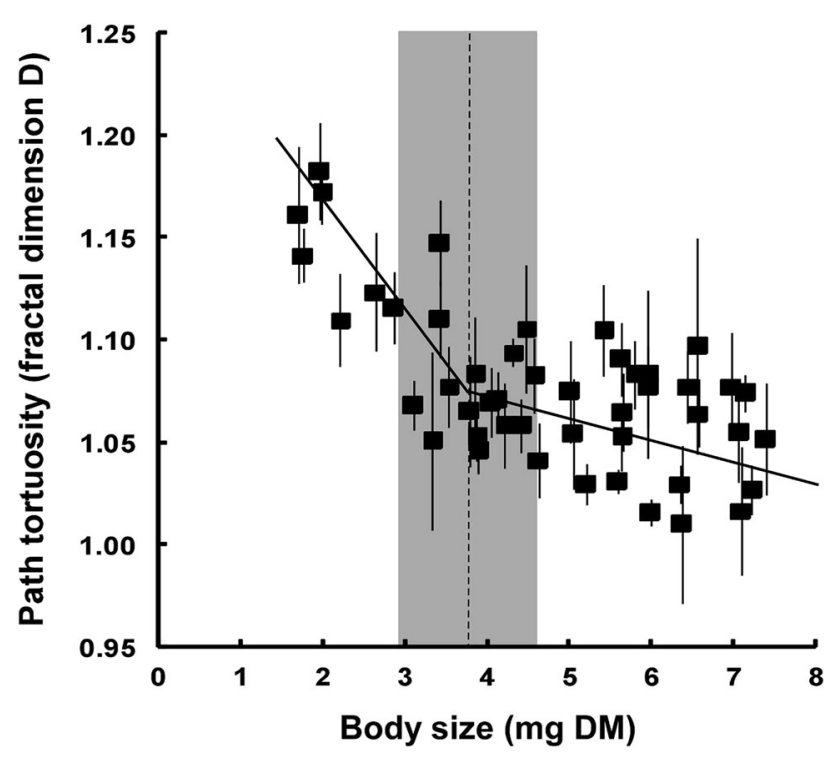

Fig. 4 Mean fractal dimension D characterizing the movement paths of Lepidurus arcticus specimens in relation to their body sizes (DM = individual dry mass, in $\mathrm{mg}$ ). Scale bars $\pm 1 \mathrm{SE}$. The continuous lines identify the segmented linear regression model fitted to the data. The dashed line identifies the breakpoint $\mathrm{C}$ characterizing the model; shaded areas show its $\pm 95 \%$ confidence interval

Table 2 Summary of regression model comparisons followed by a parsimonious procedure of selection of the best fitting model for the relationships between individual DM (in $\mathrm{mg}$ ) and the fractal dimension D of FMPs of Lepidurus arcticus

\begin{tabular}{ll}
\hline Model & Parameters \\
\hline SL_simple linear & $P=0.012$ \\
SLR_-segmental linear & $P=0.988$ \\
$\Delta$ AICc & 8.959 \\
SLR model parameters & \\
a1 & $1.235(1.176-1.294)$ \\
b1 & $-0.043(-0.064$ to -0.022$)$ \\
b2 & $-0.0064(-0.0139$ to 0.0028$)$ \\
C & $3.81(2.96-4.66)$ \\
\hline
\end{tabular}

$P$ probability that the model is correct, $\triangle A I C c$ difference between values of the second-order Akaike Information Criterion characterizing the simple and segmental linear model, respectively, $a l$ intercept, $b 1$ slope of the first regression curve, $b 2$ slope of the second regression curve, $C$ breakpoint (in $\mathrm{mg}$ ) for the segmental linear regression model. $95 \%$ confidence intervals of model parameters reported in brackets

In first instance, the relationship can be explained by simple biomechanical constraints related to the size of movement appendages. In general, manoeuvrability and maximum acceleration capacity-i.e. the ability to withstand the forces of a sudden turn at high speed without sustaining an injury-is negatively related with body size and biomechanics (Huey and Hertz 1984; Ilany and Eilam 2008; Angilletta et al. 2008; Crall et al. 2015).
However, the change in the slope of the body size-path fractal dimension $\mathrm{D}$ observed at an individual mass of $3.81 \pm 0.34 \mathrm{mg}$ (Fig. 4) suggests an alternative, not mutually exclusive explanation based on body size-related metabolic constraints. Indeed, the mass corresponds with an individual carapace length of approximately $6.6 \mathrm{~mm}$ (Mancinelli, personal observation; see also Klauser 2012). Lepidurus arcticus females in Spitsbergen reach maturity at a carapace length comprised between 4.1 and $9.0 \mathrm{~mm}$ (Lakka 2013 and literature cited); thus, the observed break falls within the size range characterizing sexual maturation. This is in agreement with previous observations on temperate amphipod and isopod species (Longo et al. 2015) summarized in Table 3. Generalizing the line of reasoning proposed in the aforementioned study, movement strategy (and the metrics used to quantify it) can be considered, at least in part, as a behavioural trait (sensu Brommer 2013), comparable with other spatial memory mechanisms (e.g. homing: Benhamou and Poucet 1995; see Carew and Sahley 1986; Vannini and Cannicci 1995; Tierney and Andrews 2013 for other examples of spatial memory in benthic invertebrates) adopted to maximize the success in foraging or escaping predators (Chapperon and Seuront 2011; Tomsic and Romano 2013). As a consequence, the complexity of the trajectories observed for L. arcticus individuals could be the result of an acquired strategy to search for food in the field and to respond to the complexity of the resource mosaic, filtered by metabolic requirements. Indeed, before the trial Arctic tadpole shrimps were starved for $24 \mathrm{~h}$, thus it is likely that the movement behaviour that they instantaneously reproduced once released in the arena was mainly driven by hunger, and only secondarily biased by escape reactions or other non-trophic behaviours. Search strategies can be casted in terms of optimal decisions within classical foraging models and metabolically driven, body size-dependent mechanisms of resource patch colonisation and abandon (Mancinelli et al. 2005, 2007 and literature cited; Alemanno et al. 2007a, b). Thus, movement behaviour within home ranges of consumers can be ultimately viewed as a strategy maximizing the encounter rate with food items that are often distributed heterogeneously. Indeed, the Arctic aquatic environment is nutrient poor and food limited (Christoffersen 2001; Calizza et al. 2016); in addition, the trophic resources included in the diet of Arctic tadpole shrimps-macrophytobenthos, macrobenthos, and zooplankton-are generally characterized by a highly heterogeneous, patchy distribution often characterized by a fractal structure (Tsuda 1995; Azovsky et al. 2000; Seuront et al. 2004; Spilmont et al. 2011; Seuront 2015 and literature cited). Our results suggest that for Arctic tadpole shrimps reaching a body mass of $3.81 \mathrm{mg}$ the changes occurring in their metabolic requirements and physiological strategies may echo on their perception of 
Table 3 Summary of the analyses performed by Longo et al. (2015) on a species of amphipod (Gammarus aequicauda) and two species of isopods (Lekanesphaera hookeri and Proasellus coxalis) testing the relationship between individual body size (ash-free dry mass, in $\mu \mathrm{g}$ ) and the fractal dimension D of FMPs

\begin{tabular}{llllll}
\hline Species & Best fitting model & $\mathrm{b} 1$ & $\mathrm{~b} 2$ & C & Biological significance \\
\hline Gammarus aequicauda $^{\mathrm{a}}$ & SLR & -0.16 & -0.006 & 0.611 & SOM \\
Lekanesphaera hookeri $^{\mathrm{a}}$ & SLR & -0.254 & -0.009 & 1.432 & SOM \\
Proasellus coxalis $^{\mathrm{b}}$ & SLR & -1.527 & -0.015 & 0.471 & SOM
\end{tabular}

SLR: segmental linear model; $\mathrm{b} 1=$ slope of the first regression curve, $\mathrm{b} 2=$ slope of the second regression curve, $\mathrm{C}=\mathrm{breakpoint}$ (in $\mu \mathrm{g}$ ) for the segmental linear regression model. The biological significance of the breakpoint ( $\mathrm{SOM}=$ size at the onset of maturity) is also reported

a Brackish species

${ }^{\mathrm{b}}$ Freshwater species

resource distribution and patchiness, ultimately inducing a shift in movement behaviour and search strategies. The connection between crucial metabolic changes occurring at the onset of maturity and variations in movement behaviour has been a posteriori demonstrated in isopods of the genus Lekanesphaera (Mancinelli 2010; Longo and Mancinelli 2014). In contrast, studies on the metabolic activity of L. arcticus are in general scant (Scholander et al. 1953; Lakka 2013), and sexual maturity-related variations are virtually unexplored. The topic needs to be further scrutinized to verify its generality, since the results of the present investigation imply that, notwithstanding the considerable differences in taxonomy and habitat compared to temperate environments, L. arcticus movement behaviour may be regulated by identical metabolically driven mechanisms as those suggested to play a crucial role for species from temperate habitats. More studies involving the analysis of Lepidurus arcticus populations from different locations and periods of the arctic summer are needed. Indeed, data on sexual maturation of Arctic tadpole shrimp females are characterized by a high spatial and temporal heterogeneity (Lakka 2013) suggesting that local conditions, in terms of, e.g. water temperature, or resource availability, may play a significant role in determining the SOM in the notostracan. Data on macroinvertebrate species from temperate areas suggest a lower variability (Sainte-Marie 1991; Longo and Mancinelli 2014). Thus, future comparative studies involving $L$. arcticus and congeneric species from temperate areas may verify whether the former is characterized by a higher sensitivity to local conditions and thus, to changes induced on its biological cycle by, e.g. climate warming. To date, there is a growing consensus on the power of animal behaviour analysis to provide effective tools and indicators of the effects determined by humaninduced environmental changes (Ugolini et al. 2012; Sih 2013; Wong and Candolin 2015). In the present study trials were performed at ambient temperature and the potential effects of temperature changes were not addressed; future experimental research activities focused on the analysis of movement behaviour in relation to size-related metabolic and physiological variations determined by changes in water temperature may provide significant information on how climate change alters the fitness of arctic populations of aquatic invertebrates and, ultimately, their functional role within ecosystems (Bradshaw and Holzapfel 2010).

Acknowledgments Permits to carry out field research in Ny-Ålesund delivered by the Governor of Svalbard ref. 2014/00729-2 a.512 (Fieldwork 2014, RIS-ID 10011) to V. P. are acknowledged. This study was supported by Consiglio Nazionale delle Ricerche, Confucio Institute-SAPIENZA Università di Roma, $6^{\circ}$ Comunità Montana del Velino. The help and co-operation of the officers and persons of the CNR D.T.A. Department and Italian Arctic Base "Dirigibile Italia" (in the person of E. Brugnoli, V. Vitale, A. Viola and E. Liberatori) is gratefully acknowledged. Thanks also to the staff of Kings Bay Marine Laboratory and to Steve Coulson for his useful advices. Financial support to G. M. was provided by FUR 2014-2015 funds. Movement analyses were carried out using the infrastructures of the Biodiversity Organization and Ecosystem Functioning (BIOforIU)node1 UNISALENTO-PON project code PONa3_00025. The authors thank Giuseppe Alfonso for insightful discussions on the ecology and biology of notostracans, and two anonymous reviewers for helpful comments that greatly improved an early version of the manuscript. This is contribution number 1 of the BIOforIU facility "Laboratorio studi su metabolismo e comportamento organismi acquatici" and is dedicated to Sofia Mancinelli, thy eternal summer shall not fade.

\section{References}

Akaike H (1974) A new look at the statistical model identification. IEEE Trans Automat Contr 19:716-723

Alemanno S, Mancinelli G, Basset A (2007a) Detritus processing in tri-trophic food chains: a modelling approach. Int Rev Hydrobiol 92:103-116. doi:10.1002/iroh.200510952

Alemanno S, Mancinelli G, Basset A (2007b) Effects of invertebrate patch use behaviour and detritus quality on reed leaf decomposition in aquatic systems: a modelling approach. Ecol Modell 205:492-506. doi:10.1016/j.ecolmodel.2007.03.009

Allema AB, Rossing WAH, van der Werf W, Heusinkveld BG, Bukovinszky T, Steingröver E, van Lenteren JC (2012) Effect of light quality on movement of Pterostichus melanarius 
(Coleoptera: Carabidae). J Appl Entomol 136:793-800. doi:10. 1111/j.1439-0418.2012.01728.x

Allema B, van der Werf W, van Lenteren JC, Hemerik L, Rossing WAH (2014) Movement behaviour of the carabid beetle Pterostichus melanarius in crops and at a habitat interface explains patterns of population redistribution in the field. PLoS ONE 9:e115751. doi:10.1371/journal.pone.0115751

Angilletta MJ, Roth TC, Wilson RS, Niehaus AC, Ribeiro PL (2008) The fast and the fractalous: speed and tortuosity trade off in running ants. Funct Ecol 22:78-83. doi:10.1111/j.1365-2435. 2007.01348.x

Augusiak J, Van den Brink PJ (2015) Studying the movement behavior of benthic macroinvertebrates with automated video tracking. Ecol Evol 5:1563-1575. doi:10.1002/ece3.1425

Azovsky AI, Chertoprood MV, Kucheruk NV, Rybnikov PV, Sapozhnikov FV (2000) Fractal properties of spatial distribution of intertidal benthic communities. Mar Biol 136:581-590. doi: $10.1007 / \mathrm{s} 002270050718$

Baird W (1852) Monograph of the family Branchipodidae, a family of crustaceans belonging to the Division Entomostraca, with a description of a new genus and species of the family, and two new species belonging to the Family Limnadiadae. Proc Zool Soc Lond 20:18-31

Barnes AD, Spey IK, Rohde L, Brose U, Dell AI (2015) Individual behaviour mediates effects of warming on movement across a fragmented landscape. Funct Ecol. doi:10.1111/1365-2435. 12474

Benhamou S, Poucet B (1995) A comparative analysis of spatial memory processes. Behav Processes 35:113-126

Borgstrøm R, Larsson P (1974) The first three instars of Lepidurus arcticus (Pallas), (Crustacea: Notostraca). Norw J Zool 22:45-52

Bradshaw WE, Holzapfel CM (2010) Light, time, and the physiology of biotic response to rapid climate change in animals. Annu Rev Physiol 72:147-166. doi:10.1146/annurev-physiol-021909135837

Brommer JE (2013) On between-individual and residual (co) variances in the study of animal personality: are you willing to take the "individual gambit"? Behav Ecol Sociobiol 67:1027-1032

Burnham KP, Anderson DR (2002) Model selection and multimodel inference: a practical information-theoretic approach. Springer, Berlin

Calizza E, Costantini ML, Rossi D, Pasquali V, Rossi L (2016) Stable isotopes and digital elevation models to study nutrient inputs in high-Arctic lakes. Rendiconti Lincei (this volume)

Carew TJ, Sahley CL (1986) Invertebrate learning and memory: from behavior to molecules. Annu Rev Neurosci 9:435-487. doi:10. 1146/annurev.ne.09.030186.002251

Chapperon C, Seuront L (2011) Variability in the motion behaviour of intertidal gastropods: ecological and evolutionary perspectives. J Mar Biol Assoc UK 91:237-244. doi:10.1017/ S002531541000007X

Chapperon C, Seuront L (2013) Temporal shifts in motion behaviour and habitat use in an intertidal gastropod. J Mar Biol Assoc UK 93:1025-1034. doi:10.1017/S0025315412000756

Christoffersen K (2001) Predation on Daphnia pulex by Lepidurus arcticus. Hydrobiologia 442:223-229. doi:10.1023/A: 1017584928657

Crall JD, Ravi S, Mountcastle AM, Combes SA (2015) Bumblebee flight performance in cluttered environments: effects of obstacle orientation, body size and acceleration. J Exp Biol 218:2728-2737. doi:10.1242/jeb.121293

Demšar U, Buchin K, Cagnacci F, Safi K, Speckmann B, Van de Weghe N, Weiskopf D, Weibel R (2015) Analysis and visualisation of movement: an interdisciplinary review. Mov Ecol 3:1-24. doi:10.1186/s40462-015-0032-y
Einarsson Á (1979) Fáein orð um skötuorm (Lepidurus arcticus (Pallas)). Náttúrufræðingurinn 49:104-111

Etzenhouser MJ, Owens MK, Spalinger DE, Murden SB (1998) Foraging behavior of browsing ruminants in a heterogeneous landscape. Landsc Ecol 13:55-64. doi:10.1023/A: 1007947405749

Hessen DO, Rueness EK, Stabell M (2004) Circumpolar analysis of morphological and genetic diversity in the Notostracan Lepidurus arcticus. Hydrobiologia 519:73-84. doi:10.1023/B:HYDR. 0000026486.16615 .06

Holyoak M, Casagrandi R, Nathan R, Revilla E, Spiegel O (2008) Trends and missing parts in the study of movement ecology. Proc Natl Acad Sci USA 105:19060-19065. doi:10.1073/pnas. 0800483105

Huey RB, Hertz PE (1984) Effects of body size and slope on acceleration of a lizard (Stellio stellio). J Exp Biol 110:113-123

Ilany A, Eilam D (2008) Wait before running for your life: defensive tactics of spiny mice (Acomys cahirinus) in evading barn owl (Tyto alba) attack. Behav Ecol Sociobiol 62:923-933. doi:10. 1007/s00265-007-0516-x

Jeanson R, Blanco S, Fournier R, Deneubourg JL, Fourcassie V, Theraulaz G (2003) A model of animal movements in a bounded space. J Theor Biol 225:443-451. doi:10.1016/s00225193(03)00277-7

Kissling WD, Pattemore DE, Hagen M (2014) Challenges and prospects in the telemetry of insects. Biol Rev 89:511-530. doi:10.1111/brv.12065

Klauser TR (2012) Population regulation in the tadpole shrimp Lepidurus arcticus. Department of Biology. Norwegian University of Science and Technology, Master Thesis, Trondheim, p 28

Lakka HK (2013) The ecology of a freshwater crustacean: Lepidurus arcticus (Brachiopoda; Notostraca) in a High Arctic region. M.Sc. Thesis, University of Helsinki, Helsinki

Lakka H-K (2015) Description of the male Lepidurus arcticus (Branchiopoda: Notostraca) and the potential role of cannibalism in defining male form and population sex ratio. J Crust Biol 35:319-329. doi:10.1163/1937240X-00002324

Lemoine NP, Burkepile DE (2012) Temperature-induced mismatches between consumption and metabolism reduce consumer fitness. Ecology 93:2483-2489. doi:10.1890/12-0375.1

Liedvogel M, Chapman BB, Muheim R, Akesson S (2013) The behavioural ecology of animal movement: reflections upon potential synergies. Anim Migr 1:39-46. doi:10.2478/ami-20130002

Longo E, Mancinelli G (2014) Size at the onset of maturity (SOM) revealed in length-weight relationships of brackish amphipods and isopods: an information theory approach. Estuar Coast Shelf Sci 136:119-128. doi:10.1016/j.ecss.2013.11.013

Longo E, Verschut T, Carrozzo L, Zotti M, Mancinelli G (2015) Inter-and intra-specific variation in movement behaviour of benthic macroinvertebrates from a transitional habitat: a laboratory experiment. Rend Lincei Sci Fis Nat. doi:10.1007/s12210015-0475-5

Mancinelli G (2009) On the importance of body size in the colonisation of ephemeral resource patches by vagile consumers. Rend Lincei Sci Fis Nat 20:139-151. doi:10.1007/s12210-0090046-8

Mancinelli G (2010) Intraspecific, size-dependent variation in the movement behaviour of a brackish-water isopod: a resource-free laboratory experiment. Mar Freshw Behav Physiol 43:321-337. doi:10.1080/10236244.2010.512728

Mancinelli G, Sabetta L, Basset A (2005) Short-term patch dynamics of macroinvertebrate colonization on decaying reed detritus in a Mediterranean lagoon (Lake Alimini Grande, Apulia, SE Italy). Mar Biol 148:271-283. doi:10.1007/s00227-005-0091-5 
Mancinelli G, Sabetta L, Basset A (2007) Colonization of ephemeral detrital patches by vagile macroinvertebrates in a brackish lake: a body size-related process? Oecologia 151:292-302. doi:10. 1007/s00442-006-0586-x

Mazzola M, Viola AP, Lanconelli C, Vitale V (2016) Atmospheric observations at the Amundsen-nobile climate change tower in Ny-Ålesund, Svalbard. Rendiconti Lincei (this volume)

McDonald WR, St Clair CC (2004) The effects of artificial and natural barriers on the movement of small mammals in Banff National Park, Canada. Oikos 105:397-407. doi:10.1111/j.00301299.2004.12640.x

Mueller T, Fagan WF (2008) Search and navigation in dynamic environments-from individual behaviors to population distributions. Oikos 117:654-664. doi:10.1111/j.2008.0030-1299.16291.x

Muggeo VMR (2008) Segmented: an R package to fit regression models with broken-line relationships. R News 8:20-25

Nams VO (2006) Detecting oriented movement of animals. Anim Behav 72:1197-1203. doi:10.1016/j.anbehav.2006.04.005

Nams VO, Bourgeois M (2004) Fractal analysis measures habitat use at different spatial scales: an example with American marten. Can J Zool 82:1738-1747. doi:10.1139/z04-167

Nathan R, Getz WM, Revilla E, Holyoak M, Kadmon R, Saltz D, Smouse PE (2008) A movement ecology paradigm for unifying organismal movement research. Proc Natl Acad Sci USA 105:19052-19059. doi:10.1073/pnas.0800375105

Nielsen UN, Wall DH (2013) The future of soil invertebrate communities in polar regions: different climate change responses in the Arctic and Antarctic? Ecol Lett 16:409-419. doi:10.1111/ele.12058

Pasquali V (2015) Locomotor activity rhythms in high arctic freshwater crustacean: Lepidurus arcticus (Branchiopoda; Notostraca). Biol Rhythm Res 46:453-458. doi:10.1080/09291016. 2015.1004842

Pasquali V, Sbordoni V (2014) High variability in the expression of circadian rhythms in a cave beetle population. Biol Rhythm Res 45:925-939

Potenza L, Mancinelli G (2010) Body mass-related shift in movement behaviour in the isopod Lekanesphaera hookeri (Isopoda, Flabellifera): a laboratory study. Ital J Zool 77:354-361. doi:10.1080/11250000903449860

Prevedello JA, Forero-Medina G, Vieira MV (2010) Movement behaviour within and beyond perceptual ranges in three small mammals: effects of matrix type and body mass. J Anim Ecol 79:1315-1323. doi:10.1111/j.1365-2656.2010.01736.x

Richardson AJ (2008) In hot water: zooplankton and climate change. ICES J Mar Sci 65:279-295. doi:10.1093/icesjms/fsn028

Rogers DC (2001) Revision of the nearctic Lepidurus (Notostraca). J Crust Biol 21:991-1006. doi:10.1163/20021975-99990192

Sainte-Marie B (1991) A review of the reproductive bionomics of aquatic gammaridean amphipods: variation of life history traits with latitude, depth, salinity and superfamily. Hydrobiologia 223:189-227. doi:10.1007/bf00047641

Sassaman C (1991) Sex ratio variation in female-biased populations of Notostracans. Hydrobiologia 212:169-179. doi:10.1007/ bf00025998

Scholander PF, Flagg W, Walters V, Irving L (1953) Climatic adaptation in arctic and tropical poikilotherms. Physiol Zool 26(1):67-92
Seuront L (2015) On uses, misuses and potential abuses of fractal analysis in zooplankton behavioral studies: a review, a critique and a few recommendations. Phys A 432:410-434. doi:10.1016/ j.physa.2015.03.007

Seuront L, Brewer M, Strickler JR (2004) Quantifying zooplankton swimming behavior: the question of scale. In: Seuront L, Strutton PG (eds) Handbook of scaling methods in aquatic ecology: measurement, analysis, simulation. CRC Press, Boca Raton, pp 333-360

Sih A (2013) Understanding variation in behavioural responses to human-induced rapid environmental change: a conceptual overview. Anim Behav 85:1077-1088. doi:10.1016/j.anbehav.2013. 02.017

Spilmont N, Seuront L, Meziane T, Welsh DT (2011) There's more to the picture than meets the eye: sampling microphytobenthos in a heterogeneous environment. Estuar Coast Shelf Sci 95:470-476. doi:10.1016/j.ecss.2011.10.021

Sugiura N (1978) Further analysis of the data by Akaike's information criterion and the finite corrections. Commun Stat A-Theor A7:13-26. doi:10.1080/03610927808827599

Tierney AJ, Andrews K (2013) Spatial behavior in male and female crayfish (Orconectes rusticus): learning strategies and memory duration. Anim Cogn 16:23-34. doi:10.1007/s10071-012-0547-1

Tomsic D, Romano A (2013) A multidisciplinary approach to learning and memory in the crab Neohelice (Chasmagnathus) granulata. In: Menzel R, Benjamin PR (eds) Invertebrate learning and memory. Academic Press, Amsterdam, pp 337-355

Tsuda A (1995) Fractal distribution of an oceanic copepod Neocalanus cristatus in the subarctic pacific. J Oceanogr 51:261-266. doi:10.1007/BF02285164

Turchin P (1996) Fractal analyses of animal movement: a critique. Ecology 77:2086-2090. doi:10.2307/2265702

Ugolini A, Pasquali V, Baroni D, Ungherese G (2012) Behavioural responses of the supralittoral amphipod Talitrus saltator (Montagu) to trace metals contamination. Ecotoxicology 21:139-147. doi:10.1007/s10646-011-0773-3

Vannini M, Cannicci S (1995) Homing behaviour and possible cognitive maps in crustacean decapods. J Exp Mar Biol Ecol 193:67-91. doi:10.1016/0022-0981(95)00111-5

With KA (1994a) Ontogenic shifts in how grasshoppers interact with landscape structure - an analysis of movement patterns. Funct Ecol 8:477-485. doi:10.2307/2390072

With KA (1994b) Using fractal analysis to assess how species perceive landscape structure. Landsc Ecol 9:25-36. doi:10.1007/ BF00135076

With KA, Cadaret SJ, Davis C (1999) Movement responses to patch structure in experimental fractal landscapes. Ecology 80:1340-1353. doi:10.2307/177079

Wojtasik B, Bryłka-Wołk M (2010) Reproduction and genetic structure of a freshwater crustacean Lepidurus arcticus from Spitsbergen. Pol Polar Res 31:33-44. doi:10.4202/ppres.2010.03

Wong BBM, Candolin U (2015) Behavioral responses to changing environments. Behav Ecol 26:665-673. doi:10.1093/beheco/ aru 183 